Neurociências

\title{
Anestesia para suscetíveis à Hipertermia Maligna
}

\author{
Anaesthesia in MH susceptible patients
}

Luiz Bomfim Pereira da Cunha

Hospital Universitário Clementino Fraga Filho, Universidade Federal do Rio de Janeiro - UFRJ.

\section{Aspectos farmacológicos do Dantrolene Sódico}

\section{Dantrolene}

\section{Oscar Pires}

Universidade de Taubaté - UNITAU, São Paulo.

\section{Introdução}

A redução dos índices de mortalidade pela hipertermia malígna (HM) é consequiência do emprego de dantrolene sódico, 1-[[[5-(4-nitrofenil)-2-furanil]-metileno]amino]-2-4imidazolidinodiona, um derivado hidantoínico lipossolúvel, sintetizado em 1967 graças a estudos de Snyder no laboratório Norwich-Eaton-Pharmaceuticals administrado por via oral ou intravenosa ${ }^{1}$.

O dantrolene sódico é um relaxante muscular que inibe a liberação de $\mathrm{Ca}^{++}$do retículo sarcoplasmático durante o acoplamento excitação-contração ${ }^{2}$ causando redução dose dependente das concentrações de cálcio intracelular em suínos ${ }^{3}$ e em humanos susceptíveis ${ }^{4}$.

A formulação para uso intravenoso é apresentada em frascos-ampola de $70 \mathrm{ml}$, contendo $20 \mathrm{mg}$ de dantrolene, 3,0g de manitol e hidróxido de sódio. O conteúdo de cada frasco ampola deve se rdiluído em 60 mlde água estéril.

\section{Farmacodinâmica}

\subsection{Músculo esquelético}

